dwells on the limitations and drawbacks of any situation as well as the glories. He might even encourage his informant in this respect by asking, in a very casual tone, about the problems. Since every situation, even the smoothest operating, has problems, this should provide fertile ground for extensive mutual exploration. One area that young engineers are particularly sensitive to, and to some degree always frustrated about, is getting their own ideas accepted. The inquirer might ask him how he's doing on this score personally, and how much frustration he feels. The conversation may then naturally turn to how susceptible the company is to new ideas in general, whether they really solicit them, etc.

If this is handled to each party's mutual satisfaction, and rapport has not lessened (or better, it seems to be increasing), the next order of business might be a frontal assault on any area or item the candidate is still worried about. For example, he might ask: "How about the atmosphere around here? How would you describe it?" Or, how about the company's methods and procedures. Progressive or behind the times, and in which areas? Is there enough of the right kind of equipment (which is rarely the case) and how much of it is obsolete?

To repeat: there is no more golden opportunity in the whole recruiting venture that this meeting and cultivation of his young counterpart. If handles with any degree of skill, the visitor will not only acquire information but also real insight into the company and it's operations that he might not otherwise get.

\section{In conclusion}

However a job seeker goes about sizing up a prospect, he should do it as systematically as possible, and apply some forethought. It was for the purpose of helping our technical student in this matter, that the check list for rating potential employers was drawn up. It is suggested that the prospective candidate go over this, make necessary additions and deletions and do some convenient rearranging, then type up the results for his own consultation. Now armed with his list and somewhat versed in the procedure and ready to apply a little effort and imagination, the technical job seeker should do very well in today's prosperous job market.

One last thing: most recruiters comment that a little summer experience helps a man immeasurably in the choice of his first full time job. He is much more versed in the realities of the situation and can handle the recruiting venture with far more acumen and confidence than can the totally inexperienced. They therefore advise that the engineering student, by hook or by crook, land a summer job in industry, even if it's just sweeping floors, and once there, keep his eyes, ears and powers of observation open and alert.

\title{
Engineers and the Military Service by the staff
}

\section{Your draft status}

In recent years, the metallurgical engineer who entered industry or sought an advanced degree invariably received a draft deferment because of the Selective Service policy of granting "occupational deferments" for those in "essential positions," and of exempting students. As a result of newly announced changes in the policies of the Selective Service, the engineer wishing to continue his education is a morethan-likely candidate for the draft. According to the new ruling, those who entered their first year of graduate school this fall will be allowed to complete only this academic year with the protection of a student deferment. Those who began their second year prior to October 1, 1967 will be allowed to complete their advanced coursework, provided they do so within five years. Those completing their master's requirements this year might do well to plan their doctoral work for a more peaceful era.

Metallurgical engineers graduating at any level and entering industry are fairly safe from the draft. While it is at the discretion of the local draft boards to determine just which jobs are in the national health safety or interest-the bases for the granting of occupational deferments - it is, and it should remain, reasonably easy for the metallurgical engineer to obtain a job thus classified and avoid military service.

\section{Drafted}

Without rank, the chances of an engineer serving in the capacity for which he is trained are slim.
Thus, those who feel they will not be employed in a job affording an occupational deferment would do well to enroll in ROTC.

\section{In the service}

For the man not totally adverse to service in the armed forces, the various branches of the United States military offer some outstanding opportunities. In almost all instances however, a commission is required, making it extremely difficult for the non com who did not take ROTC or attend Officer's Candidate School. The Army will accept certain noncommissioned personnel in some instances into its program of Technical Assistants. Here, however, competition is rigorous, and there is no certainty that the non com engineer will be accepted, as the majority of the positions are given to those anticipating extended or lifetime service, and eventual rank as an officer.

For those with commissions, some of the best opportunities are offered by the Army, namely the Army Corps of Engineers and the Army Special Officer Career Program, both of which afford the engineer a chance for diversified work and additional study. The Navy and other branches of the service also offer many departments of special interest to engineers, but they are too numerous and complex to enumerate here. For information, it is suggested that interested persons contact their local recruiting offices. 